\title{
Estrutura administrativa do governo brasileiro, cultura política e a busca pela sociedade ideal
}

\author{
José Veríssimo Romão Netto*
}

Resumo: A organização e a estrutura do governo central brasileiro mudaram drasticamente entre o período monárquico (1824-1889) e o atual período democrático (1985). No entanto, é possível identificar uma convergência teórica entre alguns autores brasileiros que têm não apenas refletido sobre a estrutura do Estado no Brasil, mas têm agido sobre ela: visconde do Uruguai (ministro e senador durante o primeiro período do Império no Brasil, um dos principais responsáveis pelo Movimento do Regresso - 1834-1840); Oliveira Vianna (burocrata e responsável por importantes mudanças na estrutura do Estado e sua relação com a sociedade brasileira durante as décadas de 1930-1940); Guerreiro Ramos (deputado federal e burocrata no Departamento de Administração e Serviço Público, peça fundamental para a reforma do Estado burocrático brasileiro 1940-1964); e Bresser-Pereira (titular do Ministério da Administração Federal e Reforma do Estado - 19951998 -, responsável pela reforma gerencial do Estado brasileiro). O que é interessante notar sobre esses autores-atores é que, durante os seus respectivos períodos e com suas percepções sobre a política e a sociedade brasileiras, eles propugnaram que, por intermédio da reforma da estrutura político-administrativa do Estado, seria possível mudar a cultura política do povo brasileiro. Durante suas ações políticas como agentes fiduciários do Estado, buscaram - dentro de seus próprios contextos históricos e políticos - o autogoverno, a democracia ou sua qualificação.

Palavras-chave: cultura política, estrutura do Estado, formação do pensamento brasileiro, governo, sociedade.

\section{Introdução}

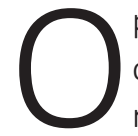
presente artigo se debruça sobre algumas das reflexões originais do visconde do Uruguai que, com nuances, se espraiaram pelo pensamento de Oliveira Vianna, Guerreiro Ramos e chegaram às de ideias Bresser-Pereira.

A opção pelos autores estudados neste artigo deve-se à sua participação no debate com importantes contribuições na literatura ${ }^{1}$, fazendo menção à discussão sobre o "problema nacional", já posto de maneira original por pensadores brasileiros desde o século XIX, em sagazes contendas acerca das relações entre instituições, da morfologia social, estrutura econômica e cultura nacional.

Algumas das questões feitas e reafirmadas com o passar do tempo pelos autores aqui apresentados se remetem a esse debate centenário, e podem ser assim descritas: Como alcançar o self-government? Como fazer a manutenção da democracia? A cultura política brasileira impediria esse trajeto? Seria, antes, necessária uma
* Pós-doutorando da Universidade de São Paulo, pesquisador permanente do Núcleo de Pesquisa em Políticas Públicas da Universidade de São Paulo. <ze_verissimo@yahoo.com.br>.

1. Esses autores atores debateram arduamente com a literatura internacional de sua época, como se pode notar em suas obras, mas a escolha para esse artigo não é a de remeter o leitor a essas referências. Como mera demonstração desses debates, todavia, nessa miríade de referências estrelam autores como Tocqueville, Chevalier, Odilon Barrot, Benjamim Constant, Jeremy Bentham, Homershan Cox, Fonblanqe, Creasy, Le Play, Guizot, Thiers, Malinoswski, Weber, Durkheim, Marx, Jung, Löwi, entre outros. 
completa revolução capitalista para que se pudesse percorrer esse caminho? Há, de fato, uma relação necessária entre desenvolvimento e democracia, ou essa equação trata, apenas, de hipótese otimista? Qual o papel do Estado nessa trajetória?

Correndo o risco de se ser injusto com diversos outros, seguem, apenas à guisa de citação, alguns dos grandes nomes que propuseram respostas a essas questões: visconde do Uruguai, Ensaio sobre o direito administrativo; Tavares Bastos, A província; Silvio Romero, História da literatura brasileira; Joaquim Nabuco, Um estadista do Império; Euclides da Cunha, Os sertões; Alberto Torres, O problema nacional brasileiro; Oliveira Vianna, Instituições políticas brasileiras; Gilberto Freyre, Casa Grande \& Senzala; Sérgio Buarque de Holanda, Raízes do Brasil; Paulo Prado, Retrato do Brasil; Nestor Duarte, A ordem privada e a organização política nacional; Caio Prado Júnior, Evolução política do Brasil; Raymundo Faoro, Os donos do poder; Vítor Nunes Leal, Coronelismo, enxada e voto; Guerreiro Ramos, Administração como estratégia do desenvolvimento; Florestan Fernandes, A revolução burguesa no Brasil; Celso Furtado, Formação econômica do Brasil...

Muitas das proposições desses autores - argumentou-se em críticas - são datadas, tanto teórica como empiricamente. Mas fato é que todos permanecem sendo lidos como fontes para reflexão contemporânea sobre problemas, hipóteses, argumentos e conceitos, marcando um ramo da reflexão política e social no Brasil que se convencionou chamar de "pensamento social" ou "pensamento político brasileiro" e que se tem demonstrado campo fértil no mundo das ciências sociais, já institucionalizado no país (Miceli, 1989; 1995; Brandão, 2007).

No presente artigo, afirma-se que é possível identificar convergências teóricas entre autores-atores políticos (o termo é de Brandão, 2007) no Brasil que supõem o desenho das estruturas administrativas do Estado como capaz de influenciar a cultura política da sociedade, notadamente Uruguai, Oliveira Vianna, Ramos e Bresser (Romão Netto, 2010).

Em comum, percepções de como interferir tanto nos processos de desenvolvimento econômico da nação como na cultura política da sociedade a partir da reforma das instituições político-administrativas brasileiras, supondo tanto o possível fortalecimento de uma cultura política democrática a partir do desenvolvimento econômico, quanto a premência de uma cultura política particular para fazer persistir a democracia e encaminhá-la para um ethos mais republicano.

Ao seguir metodologia de alinhamento de ideias tão bem demonstrada por Brandão (2007), o artigo se ocupa de alguns dos conceitos teóricos desses intelectuais e personagens políticos da história do Brasil que - a partir de proposições normativas 
do que deveria ser a sociedade brasileira, bem como de suas ações institucionais enquanto agentes fiduciários do Estado nacional - pensaram e trabalharam para a edificação do autogoverno no Brasil.

Ainda quede maneira introdutória, vale ressaltar a importância dos debates que tratam das relações entre instituições democráticas, desenvolvimento econômico e uma cultura política democrática. Diversos autores, ao longo da história das ideias, perguntaram-se se há relação possível entre o estabelecimento de instituições democráticas e uma cultura política cogente tanto ao estabelecimento dessas instituições como para sua manutenção².

A relação causal entre instituições democráticas - aqui compreendidas como as regras e os constrangimentos que regem a ordem democrática - e cultura democrática - neste trabalho entendida como as crenças, os hábitos, as ideias, os valores e as atitudes que os indivíduos mantêm durante as relações que travam entre si e em relação às próprias instituições da democracia - é motivo de cáusticos debates, ainda hoje. Essa cadeia causal revela-se ambivalente nos debates ao longo do tempo.

Podem-se notar duas correntes fundantes do debate entre as atitudes dos cidadãos e o processo de democratização. A tradição da cultura política - "para a qual o que conta é se os indivíduos apresentam ou não orientações democráticas, as quais são formadas a partir de processos de socialização que interagem com a experiência política, influindo na estabilidade ou na mudança do regime" (Romão Netto, 2010: 85) - postula que, a despeito dessas orientações terem longa duração no tempo, isso não significa que não possam ser mudadas pela pressão de "efeitos de transformação geracionais e/ou de processos de modernização econômica e social sobre os valores políticos" (Romão Netto, 2010: 85).

A segunda corrente alinha-se com as teorias institucionalistas da democracia e se propõe o estudo da institucionalização democrática a partir de dados sobre eleições, funcionamento do sistema presidencialista, relação Executivo $\times$ Legislativo e indicadores agregados de instituições políticas. Para essa corrente, os valores políticos e as orientações normativas dos indivíduos não são importantes, valendo para a análise "a eficácia das instituições com relação aos fins almejados pelos atores políticos" (Romão Netto, 2010: 86).

Desse embate, podem-se depreender algumas linhas de causalidade entre instituições e culturas democráticas: (i) a cultura causaria tanto o desenvolvimento econômico quanto a democracia; (ii) tanto o desenvolvimento quanto a cultura, independentemente, seriam necessários para tornar a democracia possível; (iii) uma cultura particular, gerada automaticamente pelo desenvolvimento econômico, seria
2. Autores clássicos já fizeram essa discussão, como Montesquieu em seu Do espírito das leis, John Stuart Mill em Considerações sobre o governo representativo e Tocqueville em A democracia na América. Contemporaneamente, Gabriel Almond e Sidney Verba (1963) afirmaram que para haver uma democracia é necessário que, além e anteriormente às instituições democráticas, exista uma "cultura cívica" disseminada entre sua população, ou seja, a existência de cidadãos ativos na vida política, com propensão à combinação de atitudes e valores como a participação, a confiança interpessoal e a deferência às autoridades. 
necessária para tornar possível a democracia; (iv) seria necessária uma cultura política particular para fazer persistir a democracia; e (v) de uma perspectiva não culturalista, a emergência e a manutenção da democracia não dependem da cultura política (Przeworski, Cheibub \& Limongi, 2003).

Uruguai, Oliveira Vianna, Ramos e Bresser supuseram que o desenho das estruturas administrativas do Estado seria capaz de influenciar a cultura política da sociedade.

\section{Convergências biográficas}

O caldo político e intelectual dos autores-atores aqui tratados tem traços comuns que, embora de difícil demonstração, apontam indícios de que suas biografias, não raro, influíram em várias preocupações que se lhes perpassaram, tais como a necessidade basilar de construção de uma ordem jurídica liberal - tão apregoada pela deontologia das cadeiras de filosofia do direito - e as decorrentes percepções sobre a morfologia social e a cultura política necessárias tanto para o estabelecimento do autogoverno como para a qualificação da democracia e o desenvolvimento econômico nacionais.

Suas ocupações também se refletiram sobre as percepções da cultura política nacional como variável dependente das estruturas político-administrativas, bem como influíram sobre as instituições das quais fizeram parte e chegaram a chefiar, como o Tribunal de Contas, os ministérios e os departamentos responsáveis pelo gerenciamento administrativo do Estado.

Todos dedicaram boa parte da vida ao tema das reformas das instituições político-administrativas nacionais, ocuparam cargos como agentes fiduciários do Estado e como representantes do povo: Uruguai foi deputado provincial, senador, presidente de província, juiz de foro, desembargador, ministro e representante diplomático do Brasil na França; Oliveira Vianna foi diretor do Fomento Agrícola do Rio de Janeiro, membro do Conselho Consultivo da mesma cidade, consultor do Ministério do Trabalho e ministro do Tribunal de Contas da União, ocupou cadeira na Acade-

3. O Dasp desempenhou papel fundamental na reorganização das estruturas administrativas do Estado brasileiro entre $1938 \mathrm{e}$ 1964, tendo sido o organizador e o iniciador da reforma burocrática do Estado brasileiro. mia Brasileira de Letras e foi sócio do Instituto Histórico e Geográfico Brasileiro; Guerreiro Ramos foi deputado federal, agente do Departamento Administrativo do Serviço Público (Dasp) $)^{3}$ e representante do Brasil na Organização das Nações Unidas (ONU); Bresser-Pereira foi presidente de banco estatal, secretário de Estado e ministro.

A isso se somam outros fatos biográficos comuns, como o de que todos têm o curso de direito por primeira forja intelectual, à exceção de Guerreiro, que tem por graduação, concomitante à de direito, o curso de ciências. Uruguai iniciou sua forma- 
ção em Coimbra, tendo terminado seus estudos no Brasil; Oliveira Vianna e Guerreiro Ramos formaram-se no Rio de Janeiro e Bresser-Pereira graduou-se em São Paulo, como Uruguai (Oliveira, 1995; Carvalho, 2002; Carvalho, 2005; Bresser-Pereira, 2004). Esse fato é importante se remontarmos o papel dos advogados e juristas ao longo da história nacional brasileira, que fizeram diversos presidentes, ministros, deputados e senadores ${ }^{4}$.

Visconde do Uruguai, nascido na França, Oliveira Vianna fluminense e Guerreiro Ramos baiano tiveram larga passagem pelo Rio de Janeiro, tendo Bernardo Pereira de Vasconcelos, Uruguai e Oliveira Vianna terminado suas vidas na Baixada Fluminense, berço do conservadorismo do Império brasileiro (Carvalho, 2002).

Oliveira Vianna foi professor universitário no Rio de Janeiro, assim como o foi Guerreiro Ramos e o é Bresser-Pereira em São Paulo; os dois últimos na mesma instituição universitária, a Fundação Getúlio Vargas, que nutre larga tradição de reflexões sobre os assuntos da administração pública.

Bresser e Guerreiro pertenceram à Ação Católica, que tinha por base o pensamento de Jacques Maritain e Alceu Amoroso Lima, que se utilizaram em suas reflexões da mesma Encíclica papal que inspirou Oliveira Vianna quando este pensou sobre direitos sociais no Brasil, a Rerum novarum, escrita por Leão XIII, em 1891 (Leal, 2004)5.

\section{Ações e reflexões}

Durante o Império, o visconde do Uruguai foi um dos responsáveis pelo Movimento do Regresso. Chamava a atenção para a confusão entre os poderes administrativo e judiciário do Estado brasileiro e justificava, a partir de uma perspectiva culturalista, a necessidade de uma reforma administrativa (Uruguai, 2002).

Nas reflexões de Uruguai, aparecem temas que são recorrentes no pensamento sobre as instituições político-administrativas do Estado brasileiro até hoje, como centralização política versus descentralização administrativa; representação da vontade nacional pelo Estado; favorecimento de agentes administrativos do Estado que tivessem vínculos com grupos específicos e já dotados de poder político (variações contemporâneas podem ser chamadas de nepotismo, clientelismo, patrimonialismo); a falta de poder para o Estado fiscalizar seus agentes fiduciários; o excesso de funcionalismo público; a colonização do poder legislativo pelas questões administrativas do governo (Uruguai, 2002).

Estas questões estão atreladas à preocupação central do visconde, "é possível desenvolver o self-government no Brasil?", que, do ponto de vista das ideias, acompa-
4. Bonavides e Paes de Andrade (1991) evidenciam o espírito deontológico da disciplina: "o direito busca fórmulas transformadoras com que alterar o status quo que fossiliza o país no imobilismo das correntes conservadoras, no estatuto político das oligarquias, no privilégio das camadas dominantes" (Bonavides \& Paes de Andrade, 1991: 12).

5. No documento, a Igreja Católica deixava de polemizar com o capitalismo como forma de produção, buscando apenas concebê-lo como despojado dos pressupostos do indivíduo liberal, abrindo espaço para a sociedade civil católica praticar a política, buscando a cristianização das relações sociais capitalistas e visando à reorganização do sistema sob o imperativo ético do comunitarismo.

Para a Rerum novarum, ver: $<$ http://www.vatican. va/holy_father/ leo_xiii/encyclicals/ documents/hf_Ixiii_enc_15051891 rerum-novarum po.html>. Acesso em: 27 Set. 2013 
nhou outros autores-atores políticos que refletiram sobre a engenharia político-administrativa do Estado brasileiro e suas influências no ethos político da sociedade nacional ao se colocarem questões referentes: "como se atingir ou reconquistar a democracia?" e, contemporaneamente, "como fortalecer a democracia?", ou "como construir o Estado republicano?"

Encontra-se uma resposta comum aos autores e agentes políticos estudados neste trabalho: a partir das reformas das instituições político-administrativas do país seria possível alcançar o objetivo de construir o Estado republicano.

Para Uruguai, a separação e especificação das atividades inerentes aos poderes Executivo e Legislativo permitiria que se desconcentrassem as atividades de gestão de assuntos locais, por ele chamados de "interesses especiais", em oposição aos "interesses comuns", que diriam respeito a todas as partes da nação, o que traria mais efetividade, prontidão e economia na gestão dos assuntos públicos do que se o governo central os tratasse diretamente.

Todavia, a desconcentração administrativa não deveria ser seguida de uma descentralização política, uma vez que a convergência da vontade política do Império exprimiria ideia de organização e também de finalidade comum nas atividades do Estado, além de garantir a força necessária para o direcionamento dos interesses comuns da nação (Uruguai, 2002).

Essas reformas não deveriam implantar in totum o autogoverno nas localidades do país, uma vez que a sociedade brasileira, contrariamente às inglesa e norte-americana, não tinha o hábito da administração comunitária da coisa pública, sequer da eleição de gestores locais. Dever-se-iam seguir as regras constitucionais que garantiriam a participação do povo nas decisões locais, mas essa participação, que deveria ser lentamente implantada, ocorreria sempre pela tutela do poder central, por intermédio tanto da nomeação de agentes administrativos nas províncias, quanto pela criação de instituições político-administrativas que assegurassem a justiça e a imparcialidade das ações pretendidas (Uruguai, 2002).

Para tanto, a fórmula proposta pelo visconde é certeira:

Nos países nos quais ainda não estão difundidos em todas as classes da sociedade aqueles hábitos de ordem e legalidade, únicos que podem colocar as liberdades públicas fora do alcance das invasões do poder, dos caprichos da multidão e dos botes dos ambiciosos, e que não estão, portanto, devidamente habilitados para o self-government, é preciso começar a introduzi-lo pouco a pouco, e sujeitar esses ensaios a uma certa tutela e a certos corretivos. 
Não convém proscrevê-lo, porque, em termos hábeis, tem grandes vantagens, e nem o governo central, principalmente em países extensos e pouco povoados, pode administrar tudo. É preciso ir educando o povo, habituando-o pouco a pouco a gerir seus negócios (Uruguai, 2002: 492, grifos meus).

Oliveira Vianna discorda frontalmente do prognóstico do visconde, alegando que a desconcentração administrativa fortaleceria o que chamou de "clãs rurais" no país ${ }^{6}$. Concorda, todavia, com o diagnóstico culturalista de que o povo brasileiro necessitava ser educado para o self-government (Oliveira Vianna, 1973).

Não haveria no Brasil a cultura política da participação na gestão da coisa pública, tão cara aos povos de origem saxônica (também utilizados como exemplo por Uruguai) como os ingleses e os norte-americanos. Seria o povo brasileiro um povo "transplantado", sem fatores geográficos, históricos e institucionais, sem oportunidade de contribuir para o surgimento de uma solidariedade social do tipo livre-associativista, fundamentada em hábitos, ideias e práticas culturais que favoreceriam instituições de autogoverno, como o exercício espontâneo do sufrágio, as propagandas preparatórias para disputa eleitoral e a eleição de gestores locais (Oliveira Vianna, v. 1 e 2, 1987a; 1987b).

Mesmo discordando da estratégia de treinamento do "povo-massa" por intermédio da desconcentração administrativa proposta por Uruguai, o mote da reforma das instituições administrativas brasileiras era ponto central da avaliação de Oliveira Vianna, que julgou que o Estado, por meio de suas atividades político-administrativas, seria o único ente capaz de proteger esse povo da tirania dos chefes de clãs.

Essas reformas levariam o Brasil à categoria de nação liberal-democrática, de maneira paulatina, para o que seria necessário que se adaptassem as instituições político-administrativas do Brasil ao que ele chamou de "direito-costume"7 do povo brasileiro.

A mudança seria possível a partir do momento que se admitisse que no Brasil sempre se tentou importar instituições políticas de países com tradição de self-government - o que o autor chamou de "direito-lei", uma vez que estariam apenas inscritas nas diversas Constituições do país, não sendo praticadas por não fazerem parte do caldo cultural do povo - e se passasse a educar o povo-massa a partir de uma prática "autoritária" por parte do Estado; prática através da qual o Estado, utilizando-se de métodos coercitivos, obrigaria o povo a praticar certas inovações.

Medidas como a instauração de concursos para provimento de cargos públicos, a instituição de Tribunais Regionais, a constituição de um estatuto para o funciona-
6. O dito "clã rural" seria o responsável pela organização do latifúndio no Brasil, sustentando a origem de uma cultura política clientelista, personalista e patrimonialista do Estado nacional.

7. "Direito-lei" e "direito-costume" marcam uma diferença entre um "país legal" e um "país real". Segundo o autor, o primeiro "país" trata das interpretações

liberais, ou

liberalizantes, feitas por diversos agentes políticos ao longo da história nacional, que foram inscritas nas constituições brasileiras como critério de realidade social quando o

"direito-costume", atrelado às realidades sociais do povo-massa, suplantava o "direitolei" inscrito nessas constituições. 
8. Em adendo do

"Problemas de política objetiva", o ministro Ruben Rosa, do Tribunal de Contas, enumera nada menos do que 29 normas propostas por Oliveira Vianna no referido livro que influenciaram as Constituições de 1934, 1937 e 1946, sem contar as legislações estaduais. Entre essas propostas, encontram-se a constituição de Tribunais Regionais e a instituição de conselhos técnicos (Carta de 1934), a elevação do mandato do presidente da República (Constituição de 1937), a constituição de estatuto dos funcionários públicos e a obrigação dos concursos para provimento de cargos públicos (presente na letra das Cartas Magnas de 1934, 1937 e 1946), dentre outras (Oliveira Vianna, 1947: 275299). lismo público, a criação de conselhos técnicos, a garantia constitucional de direitos sociais e a obrigação da organização trabalhista como a sindical urbana, por exemplo, auxiliariam no desenvolvimento de uma cultura política liberal-democrática da sociedade brasileira (Oliveira Vianna, 1947).

A proposta normativa de Oliveira Vianna e o fundamento de seus críticos para enviá-lo ao inferno dos julgamentos é um poder central forte o suficiente para fazer frente aos clãs locais, criando, a partir do centro, a sociedade liberal que até então não se conseguira estabelecer:

[...] fundir moralmente o povo na consciência perfeita e clara da sua unidade nacional e no sentimento político de um alto destino histórico. Esse alto sentimento e essa clara e perfeita consciência só serão realizados pela ação lenta e contínua do Estado - um Estado soberano, incontrastável, centralizado, unitário, capaz de impor-se a todo o país pelo prestígio fascinante de uma grande missão nacional (Oliveira Vianna, 1973: 259).

Uruguai e Oliveira Vianna julgaram, cada um a seu modo, que uma cultura política liberal do povo brasileiro seria, por um lado, variável independente para o estabelecimento do autogoverno no país, mas, por outro, dependeria da reforma das instituições do Estado para ser gerada e fortalecida nesse sentido.

As prescrições de Oliveira Vianna, que têm fundamento nas reflexões, diagnósticos e práticas do visconde do Uruguai, encontraram solo fértil no Brasil tão só a partir dos anos $1930^{8}$.

Com o fim da Segunda Guerra Mundial, em 1945, mesmo com as instituições fundamentais da democracia operando no Brasil - como o voto (ainda que não universal), os direitos à organização política (mesmo que não plena, pois o PCB mantinha-se na clandestinidade) e a liberdade de imprensa -, acatava-se o diagnóstico culturalista de que o povo brasileiro padecia de uma inaptidão cultural à democracia. Um adendo a esse problema nacional se colocaria a partir de então, e a receita para a constituição do cidadão brasileiro deixaria de ser o treinamento de um povo amorfo pelas instituições político-administrativas desenhadas pelas elites políticas nacionais e passaria a ser o desenvolvimento econômico.

Ideias de organismos internacionais, como a Comissão Econômica para a América Latina e o Caribe (Cepal), e nacionais, como o Instituto Superior de Estudos Brasileiros (Iseb), produziram explicações para as resistências ao desenvolvimento econômico dos países periféricos, especificando quais seriam os condicionantes estruturais do desenvolvimento (Weffort, 2006). 
O "problema brasileiro" aparecia nas produções do Iseb não apenas enquanto preocupações político-culturais, mas também como inquietações relacionadas à sua estrutura econômica e social, como as consequências trazidas pela abolição da escravatura e da imigração estrangeira; a formação de um mercado de trabalho nacional livre; as dificuldades de importação causadas pelas grandes guerras mundiais e as crises cambiais. Esses fatores teriam gerado uma convergência de interesses entre diversos campos da sociedade brasileira - proletariado, campesinato, burguesia e classe média - que passaram a ter seus interesses representados pelo desenvolvimento (Bresser-Pereira, Maravall \& Pzeworski, 1994).

Contudo, os traços culturais da sociedade brasileira, segundo as produções do Iseb, foram intensificados com esse quadro favorável ao desenvolvimento que estrangulou a máquina do Estado, favorecendo uma política de clientela e deformando o serviço público (Weffort, 2006).

Isebiano eminente, Guerreiro Ramos, valendo-se das reflexões de Uruguai e Oliveira Vianna, uniu as preocupações de pensar o povo brasileiro enquanto categoria autônoma àquelas trazidas pelas teorias desenvolvimentistas, afirmando que o "problema nacional" só teria ocorrido após a independência e que se teria constituído pela vontade do Estado, uma vez que este se teria formado antes da sociedade e esta por vontade daquele.

A partir das reflexões que produziu por sua longa estada no Departamento Administrativo do Serviço Público, Guerreiro Ramos erigiu sólida teoria sobre a identidade nacional e as melhores estratégias para o desenvolvimento nacional. Utilizando-se de conceitos das áreas de conhecimento da administração e da sociologia, identificou necessidades de transformação na sociedade brasileira (Ramos, 1966).

Mesmo com uma perspectiva positiva acerca das capacidades desse povo, suas potencialidades necessitavam ser despertadas e a receita para retirá-lo de um estado de entropia para sua realização enquanto agente político passaria pelo desenvolvimento nacional. $\mathrm{O}$ agente por excelência para favorecer esse desenvolvimento seria o Estado. A estratégia para o Estado conduzir a nação ao desenvolvimento e à democratização seria a racionalização das estruturas político-administrativas do Estado, a partir da reforma dessas (Ramos, 1966).

Dever-se-ia implementar, no Brasil, um modelo de gestão que propiciasse a impessoalidade, a excelência produtiva e a autonomia, por intermédio de reformas administrativas que estabelecessem o mérito como critério de contratação de funcionários para os quadros da burocracia, bem como o desenvolvimento de carreiras para a mesma, visando o término do privatismo da coisa pública e a implementação de 
uma "cultura do moderno", que programasse e organizasse a produção nacional a partir do Estado, via empresas públicas.

Esses procedimentos favoreceriam tanto o surgimento quanto a identificação, por parte dos agentes do Estado, das demandas sociais legítimas, uma vez que esse Estado, sem as reformas necessárias, estava tomado por relações oligárquicas de dominação, patrimonialistas, e por formas e hábitos culturais que impediam a participação de outras classes nos assuntos do Estado (Ramos, 1960).

Além da identificação das demandas legítimas do povo por parte do Estado, as reformas necessárias à suplantação do Estado patrimonialista descrito por Guerreiro Ramos favoreceriam o fortalecimento do próprio papel do Estado, uma vez que dele emanaria a racionalidade para as reformas, bem como dele seria o papel de coordenação para planejar e melhor executar a disposição ótima dos fatores de produção em um contexto capitalista (Ramos, 1966).

As outras classes sociais - que não a elite acostumada a colonizar o Estado - deveriam ser formadas enquanto categoria política para o que o desenvolvimento econômico, favorecido pelas reformas das instituições político-administrativas do Estado, ao engendrar uma fase capitalista de desenvolvimento econômico-social, forjasse naturalmente essas novas classes ao integrar o povo em um mercado próprio.

Ao propugnar as possibilidades da administração racional como forma de intervenção social, ocupou-se da erosão da ordem social, do papel dos sociólogos em conter esses desequilíbrios; em manter o controle social e a consequente garantia de convivência social democrática; e em esclarecer os dirigentes sobre o papel de uma intelligentzia no Brasil.

Uma sociedade de que estão ausentes as forças de integração espontânea dos indivíduos e dos grupos, só poderá manter-se ou por métodos policiais ou por métodos administrativos compreensivos. A preponderância de uns ou de outros dependerá da preparação sociológica dos grupos governantes. Não estou certo de que o problema tecnológico do governo se resolveria mediante a fórmula, um tanto platônica, de pôr os sociólogos no lugar dos governantes, mas, com certeza, sua solução será tanto mais assegurada quanto maior for a capacidade dos dirigentes de assimilarem os conhecimentos recém-atingidos pelas ciências sociais. Por este motivo, cresce de importância o papel dos órgãos de Estado maior, naturalmente incumbidos de pôr ao alcance dos governantes os conhecimentos técnicos e científicos das ciências sociais, sem os quais a administração da sociedade será aleatória e torpe (Ramos, 1946: 161-162). 
A percepção da necessidade de uma estrutura burocrática forte para a gestão da coisa pública no Brasil acompanhou o planejamento e as reformas levadas a termo durante o regime militar, especialmente com o Decreto-Lei n. 200 , que visava à criação de uma nova burocracia, bem como ao fortalecimento do crescimento econômico, por intermédio da criação das empresas e fundações estatais ${ }^{9}$.

De uma perspectiva histórica, após o advento do regime militar (1964), seguiu-se no Brasil um amplo movimento sociopolítico de retomada da democracia, estabelecido entre 1974 e 1985, culminando com a Constituição de 1988. A institucionalização das ciências sociais no país, em conformidade com a sociedade nacional, também galgou outro patamar, solidificando seus conhecimentos e estruturando consistente programa de pesquisa (Miceli, 1989; 1995). Assim, um novo problema se colocava na agenda de pesquisas sociais no Brasil: como consolidar as instituições democráticas, evitando-se o nefasto ciclo entre regimes autoritários e democráticos que assolaram o país desde que se tornou uma república?

Diversos pesquisadores teceram suas análises, tendo convergido, com nuances, ao prognóstico receitado por Uruguai, Oliveira Vianna e Guerreiro Ramos: para se estabilizar e fortalecer a democracia no Brasil, seria mister uma reforma nas instituições administrativas de Estado (Sola, 1994; Diniz \& Azevedo, 1997; O’Donnel \& Schimitter, 1988).

Estudos também demonstraram a percepção de uma mudança na morfologia social brasileira, principalmente a partir da década de 1970 (Moisés, 1995), e também no que diz respeito à organização da sociedade, a partir de então usualmente chamada de "nova sociedade civil" (Sader, 1988).

Essa sociedade civil, para além da categoria de análise sociológica, demonstrou-se fator fundamental no processo de democratização nacional entre os anos 19701980; os pesquisadores não puderam negar sua existência, dadas evidências como as expressivas votações colhidas pelo Movimento Democrático Brasileiro (MDB) ${ }^{10} \mathrm{a}$ partir de 1974, os movimentos de carestia, de mães, das Centrais Eclesiais de Base da Igreja Católica, o fortalecimento do sindicalismo urbano e a criação de novos partidos políticos, a exemplo do Partido dos Trabalhadores (Sader, 1988).

As relações entre essa sociedade civil e as estruturas administrativas e políticas do governo foram muito estudadas e debatidas, a ponto de se ter cunhado o termo "ingovernabilidade" para se tratar da pressão exagerada de demandas sociais e de participação dessa nova categoria de cidadãos que ora se apresentava, bem como da incapacidade do governo em atendê-las, o que gerava insatisfação generalizada na população (Diniz \& Azevedo, 1997).
9. O Decreto-

Lei $n . \circ 200$ foi

o instrumento

legal utilizado

pelos militares

para a criação e o

fortalecimento das

empresas, autarquias

e fundações públicas.

10. O MDB foi, ao

longo de todo o período do Regime

Militar, o partido

formal e legal

de oposição ao regime, que estava

forçosamente

organizado em uma estrutura política

bipartidária. 
11. Não é demais lembrar que, a partir da Constituição de 1988, o Brasil é uma república federativa que exerce seu poder a partir de representantes eleitos ou por iniciativa direta.

12. Com a assimilação do Mare pelo Ministério do Planejamento e Orçamento, a fusão gerou o Ministério do Planejamento, Orçamento e Gestão (1999).
O remédio para o problema envolveria tanto a adequada mobilização de recursos institucionais do Estado como a capacidade de coalizões políticas realizadas no sentido da manutenção da democracia, somando-se, desta feita, as dimensões técnicas e políticas da ordem democrática à eficiência político-administrativa do Estado; em outras palavras, precisar-se-ia elevar a capacidade de governança e governabilidade deste novo Estado democrático (Diniz \& Azevedo, 1997).

As reformas das instituições político-administrativas propostas pela Constituição de 1988 para sanar os problemas acima descritos foram: o sufrágio universal, a ampliação de direitos sociais, a descentralização administrativa e financeira, a reforma do serviço civil, consecutivas tentativas de contenção do déficit público, políticas de abertura comercial (Bresser-Pereira, 1995a).

A grande novidade instaurada com o advento da Nova República foi a ampliação de instrumentos institucionalizados de participação popular a partir do Estado ${ }^{11}$, onde, no bojo de suas reformas, implementaram-se diversos mecanismos de participação popular direta visando à faltante governabilidade, tais como conselhos de políticas públicas, ouvidorias, orçamentos participativos, emenda constitucional por iniciativa popular, referendos e plebiscitos (Romão Netto, 2006).

As preocupações em estabelecer novos mecanismos de relacionamento com a sociedade acompanharam os governos brasileiros até o projeto de reforma do Estado proposto pelo Ministério da Administração Federal e Reforma do Estado (Mare), liderado por Bresser-Pereira desde sua origem (1995) até $1998^{12}$.

A produção intelectual de Bresser permite que se apontem que os diversos temas que vêm sendo discutidos até então sejam vistos não como síntese, mas como ponto de convergência e realinhamento de conceitos fundamentais dessa tão debatida relação entre sociedade e Estado no Brasil, quando se pensam as reformas do Estado brasileiro.

É necessário ressaltar que as análises de Bresser-Pereira - que fundamentaram sua atuação e sofreram modificações com o passar dos anos -, foram elaboradas nesse novo contexto social já descrito, quando se as comparam com autores como visconde do Uruguai, Oliveira Vianna e Guerreiro Ramos.

Nesse sentido, o Brasil já havia alcançado o patamar de sociedade liberal e democrática, tanto do ponto de vista dos direitos de cidadania como do da economia. As instituições democráticas estavam não apenas desenhadas, mas implantadas e em funcionamento; o povo, por sua vez, deixou de ser categoria deontológica, coordenou-se e demonstrou papel fundamental na organização da nova ordem democrática. Ainda assim, diversas das preocupações bresserianas fazem eco e encontram solo 
fértil nas reflexões dos autores que vêm sendo analisados neste artigo, dando nova roupagem a questionamentos já feitos: as instituições político-administrativas são suficientes tanto para a qualificação da democracia brasileira quanto para o fortalecimento de um novo modelo nacional de desenvolvimento? Como uma reforma institucional poderia auxiliar no desenvolvimento de uma nação republicana a partir do fortalecimento dos valores democráticos da sociedade? É possível que se fortaleça a cidadania a partir da reforma do Estado?

Para responder a essas questões, Bresser-Pereira associa elementos de reflexão econômicos, políticos, sociais e culturais, tecendo uma proposta normativa para a sociedade brasileira a partir de análises de processos históricos da formação político-econômica do Brasil (Bresser-Pereira, 2009). Seu diagnóstico fundamenta-se em um contexto de crise do Estado, que se teria iniciado em 1979 com o segundo choque do petróleo e pode ser definido fundamentalmente por: (i) crise fiscal do Estado - perda do crédito público e poupança pública negativa; (ii) crise do modo de intervenção da economia e do social - o esgotamento do modelo protecionista de substituição de importações; (iii) crise do aparelho do Estado - clientelismo, profissionalização incompleta e enrijecimento burocrático extremo; e (iv) crise sociopolítica, que foi o colapso da coalizão política entre os militares e o empresariado e que teria sustentado o regime autoritário (Bresser-Pereira, 1995a; 1995b).

Seu prognóstico foi uma "reforma do Estado" que qualificasse as atividades e a estrutura administrativa do Estado em (i) um núcleo estratégico; (ii) atividades exclusivas do Estado; (iii) serviços não exclusivos do Estado; e (iv) produção de bens e serviços para o mercado (Bresser-Pereira, 2009; Brasil, 1995).

Os serviços não exclusivos (como saúde, cultura, educação, ciência e tecnologia) deveriam ser desconcentrados e executados pelo setor público não estatal, que, organizado na sociedade civil, também seria o responsável pelo controle social dessas políticas $^{13}$. Essa articulação entre as instituições do Estado e o público não estatal seria o motor de transformação da cultura política da sociedade atual para uma mais republicana (Bresser-Pereira \& Grau, 1999; Bresser-Pereira, 2009).

Argumenta o autor que o estudo das instituições ganhou mais importância no mundo contemporâneo devido ao fato observado de que por intermédio delas podem ser alcançados resultados sociais, bem como objetivos políticos fundamentais para as sociedades modernas podem ser alcançados, como a ordem pública, a liberdade, o bem-estar e a justiça.

Enquanto a mudança das duas outras instâncias - a estrutural e a cultural - só se alteram no longo prazo, é possível mudar comportamentos e atingir resultados substanciais com a adoção de institui-
13. Público não estatal porque são organizações que não fazem parte do Estado e não têm finalidades lucrativas. Sociedade civil, para o autor, é a sociedade politicamente organizada voltada para os objetivos de liberdade individual, justiça social e proteção ao meio ambiente. 
ções adequadas [...]. Esse pressuposto terá um travo conservador se for entendido de forma absoluta, mas será realista se, a partir dele, compreendermos que as instituições podem mudar estrutura e cultura, mas só o farão se não as ignorarem, mas procurarem, modesta e realisticamente, influir sobre elas (Bresser-Pereira, 2004: 8).

14. O Movimento do Regresso reuniu políticos originalmente liberais do Império, entre os anos 1830 e 1840, visando à recentralização dos poderes do Imperador, especialmente 0 Poder Moderador, considerado como o quarto poder, ao lado do Legislativo, do Judiciário e do Executivo.

\section{Reformas administrativas e cultura política}

Uruguai iniciou suas reflexões sobre o Brasil com elã liberal, tendo sido, todavia, um dos grandes representantes do Movimento do Regresso ${ }^{14}$, devido às suas análises de que não haveria a cultura política necessária ao povo brasileiro para capacitá-lo ao self-government (Carvalho, 2002).

Oliveira Vianna (1987, v. 1 e 2) corrobora essa tese, retroagindo no tempo às deliberações dos druidas sob as sombras dos carvalhos britânicos, para justificar o argumento culturalista de que o "povo-massa" brasileiro não possuía a cultura política necessária para o autogoverno do país. Já Guerreiro Ramos (1960), mesmo qualificando a inexistência de uma tal cultura no povo brasileiro, reflete messianicamente sobre o papel de uma intelligentzia que levaria esse povo a uma identificação e organização, ao favorecer o desenvolvimento econômico nacional.

É a partir dessa época (1950), com a aclamação das teses da Cepal e do Iseb, com fundamento nas análises de economistas como Celso Furtado, que o desenvolvimento econômico surge como variável independente em relação à cultura política, ganhando status de potencial modificador da cultura política nacional (Weffort, 2006).

O capitalismo, percebido como desdobramento natural a partir do desenvolvimento econômico, traria a possibilidade do surgimento de novas classes sociais, conscientes de si e organizadas enquanto tal, com valores democráticos arraigados e propensos ao comunitarismo e à igualdade social, o que favoreceria o estabelecimento da democracia no país.

Bresser-Pereira, revisitando argumentos isebianos e cepalinos, une todas essas categorias (instituições, economia e cultura política) que passam a ser percebidas pelo autor como constantes de um único movimento social encetado, dialeticamente ao longo da história nacional, tanto pelas estruturas do Estado como pela sociedade civil (Bresser-Pereira, 2002).

Todos os autores-atores apresentados partem do mesmo ponto ao identificarem como central a reforma das instituições político-administrativas do Estado nacional, para que se iniciem mudanças estruturais e culturais na sociedade brasileira. 
A reforma geraria, fortaleceria valores liberais, de autogoverno ou republicanos, a partir de mudanças como a desconcentração de instituições administrativas separadas do Poder Legislativo, como demonstrou Uruguai (2002). A organização comunitária agiria a partir das orientações do centro do poder, como afirmou Oliveira Vianna (1987); com o surgimento de uma nova classe social derivada do desenvolvimento econômico, como desejou Guerreiro Ramos (1960); ou a partir da participação social nos assuntos do Estado e do desenvolvimento econômico, de acordo com Bresser-Pereira (2009).

Ao tratar de um "Estado forte" no núcleo estratégico do aparelho do Estado, responsável pelas decisões que condizem ao interesse nacional, as reflexões de Bresser-Pereira ecoam as preocupações de Uruguai em relação à questão da centralização política e da desconcentração administrativa no Império.

As referências possíveis entre a categoria "concentração política" do visconde e as teses de Bresser estendem-se à questão de tipificação feita pelo segundo, ao separar as atividades do Estado em atividades exclusivas e serviços não exclusivos. As primeiras tratam da capacidade de executar os poderes extroversos de regulamentação, fiscalização e fomento, que são percebidas a partir da sociedade, e que emanam desse centro em forma de diretrizes jurídicas, políticas, administrativas e fiscais. Já os serviços não exclusivos, por sua característica de produzirem ganhos que não podem ser apropriados pelo mercado por não poderem se transformar em lucro, devem ser financiados pelo Estado e executados em parceria com o "público não estatal" através da desconcentração dos serviços, para utilizar termo de Uruguai. Estes se tornariam mais eficientes, fortaleceriam práticas de mecanismos que privilegiariam a participação da sociedade tanto na formulação como na avaliação do desempenho da organização social prestadora do serviço, favorecendo o controle social (Bresser-Pereira, 2009).

Ficam claras as relações traçadas entre o visconde do Uruguai e Bresser-Pereira e suas reflexões sobre a necessidade de que a vontade política emane de um núcleo, ou centro, e de que reflita o bem comum percebido por esse núcleo político e derivado da sociedade, bem como o fato de que os assuntos chamados "interesses especiais" pelo visconde e "serviços não exclusivos do Estado" por Bresser, para além de tornarem as políticas públicas mais eficientes, também serviriam como convite e estímulo à participação do cidadão nos assuntos do Estado.

Nas propostas de reformas político-administrativas feitas por Uruguai também se evidencia uma preocupação que motivou todos os autores-atores aqui estudados: o patrimonialismo no serviço público. Certo é que Uruguai não se utiliza do termo patrimonialismo para falar do problema, ocupando-se, antes, de reformas que im- 
pedissem juízes municipais, "criaturas da cabala de uma das parcialidades do lugar" (Uruguai, 2002), de serem detentores de poder exclusivo sobre o julgamento de crimes de responsabilidade administrativa dos funcionários públicos da mesma localidade, ou seja, também pertencentes à mesma cabala.

Oliveira Vianna (1947) foi contundente em relação a esse assunto, tendo chegado a iniciar a reforma burocrática do Estado ao propor, pela primeira vez no Brasil, que os cargos públicos fossem preenchidos de maneira meritocrática e pública, por meio de concursos, ponto que foi reforçado pela reforma administrativa feita pelo Dasp e largamente incentivada por Guerreiro Ramos (1966).

O ponto é nevrálgico na obra de Bresser-Pereira que, mesmo reconhecendo o empenho da Reforma Burocrática (da qual Ramos foi peça central em sua passagem pelo Dasp), no sentido de conter o patrimonialismo do Estado brasileiro, faz uma crítica ao Decreto-Lei n.․ 200/1967, ao afirmar que esse critério público foi perdido devido à inflexibilidade e à generalização das normas administrativas (Bresser-Pereira 1995b).

A questão da regulação das atividades do Estado surge com força nas obras de Uruguai, Oliveira Vianna e Bresser-Pereira, ponto no qual os autores convergem para uma percepção de que as reformas político-administrativas por eles propostas facilitariam essa regulação.

O visconde do Uruguai e Oliveira Vianna concordam que o mecanismo central para essa regulação é o Poder Judiciário, que, para exercer tal função, deveria ser fortalecido; mas vale lembrar que Oliveira Vianna também favoreceu em suas atividades o exercício da regulação do Executivo e do Legislativo, tendo ele próprio sido ministro do Tribunal de Contas da União (Uruguai, 2002; Oliveira Vianna, 1947).

Bresser, reconhecendo a legitimidade de regulação judicial e do Executivo, incrementa o argumento falando da regulação que emana de uma nova sociedade - liberal, democrática e republicana - surgida a partir do estímulo à participação na coisa

15. O conceito diz respeito aos procedimentos e mecanismos por intermédio dos quais eleitores e sociedade se responsabilizam e controlam a conduta dos que detêm o poder. pública e que, por meio dessa participação, eleva o accountability ${ }^{15}$ dos agentes do Estado e dos representantes do povo.

Essa perspectiva, como dito, também é levantada por Uruguai ao afirmar que a intervenção de particulares nos negócios de suas respectivas províncias, em assuntos imediatamente vinculados a seus interesses, poderia elevar as possibilidades de autogoverno no país, mas essas intervenções, justamente por haver uma falta de cultura política para o self-government, deveriam ser introduzidas aos poucos, com tutela e sujeita a corretivos (Uruguai, 2002). 
Oliveira Vianna corrobora a tese de que se possa "educar" o povo para sua participação na gestão da coisa pública. Para tanto, propõe a estratégia de que reformas legislativas aplicassem sanções àqueles que não cumprissem as regras, bem como o Estado deveria fortalecer os direitos sociais e organizar os cidadãos em associações e sindicatos para que esses desenvolvessem a cultura da participação e da associação (Oliveira Vianna, v. 1 e 2, 1987a; 1987b).

Essa formação de uma cultura política liberal que vem sendo discutida é receita para um problema mencionado por Oliveira Vianna no Brasil, uma diferença entre um "país legal" e um "país real", que opõe interpretações liberalizantes sobre o país à realidade cultural do "povo-massa", o chamado "direito-costume" (Oliveira Vianna, v. 1 e 2, 1987a; 1987b).

Guerreiro Ramos chamou essa característica nacional de formalismo, ou seja, a discrepância entre a conduta concreta e a norma prescrita que se supõe regulá-la, afirmando ser este um traço cultural nacional, incluindo-se aí as elites política e econômica do país (Ramos, 1966).

Oliveira Vianna e Guerreiro Ramos talvez tenham, em suas obras de maturidade Instituições políticas brasileiras e Administração e estratégia do desenvolvimento, respectivamente -, desenvolvido com mais força e clareza a relação entre mudança na cultura política nacional via reforma das instituições político-administrativas no Brasil. Mas, como se está defendendo neste artigo, todos os autores passaram por essa relação, qual seja, reformas institucionais levariam o Brasil ao patamar de nação liberal-democrática.

Bresser-Pereira relaciona - a partir de forte inspiração isebiana -, o surgimento desse ethos liberal-democrático ao desenvolvimento e à sustentação do capitalismo no Brasil. Esse "espírito público", almejado por todos os autores aqui estudados, seria fruto de um novo acordo de classes alcançado, historicamente, entre os capitalistas, a classe política, o proletariado nacional e a burocracia. Mais do que isso: a Reforma Gerencial do Estado, somada a esse percurso histórico, favoreceria a possibilidade de fortalecimento da cultura política e dos direitos clássicos de cidadania identificados por T. H. Marshall (civis, políticos e sociais), bem como do que Bresser chama de "direitos republicanos"16.

Bresser-Pereira argumenta que o Estado social democrático foi fundamental para a ordenação dessa cidadania; mas diverge de Oliveira Vianna, por exemplo, quando esse identifica que seria função exclusiva da elite política do Estado reformar as instituições brasileiras, visando à modificação da cultura política nacional e ao desenvolvimento econômico da nação.
16. Para uma crítica sobre a avaliação de Bresser-Pereira sobre a categorização dos direitos republicanos como uma nova forma de direitos, ver Marcus André Melo (2004). Para a categorização de Marshall, ver T. H. Marshall (1967). 
Por outro lado, Bresser corrobora reflexões de todos os autores-atores em relação à formação de quadros de uma burocracia nacional, bem como a delimitação de suas áreas de atuação, para que esses viessem a modernizar as estruturas do Estado; Uruguai defendeu as delimitações das atividades administrativas e judiciárias; Oliveira Vianna pensou em categorias exclusivas de Estado, como a fiscal e defendeu os concursos para ingresso no aparelho de governo; Guerreiro Ramos foi partidário da formação de quadros profissionais que compreendessem questões como a segurança nacional, o Estado democrático e o desenvolvimento econômico, almejando, assim, a consolidação do sistema capitalista industrial e as reformas sociais que conduziriam um povo disforme à organização e, consequentemente, à democracia.

Essas mudanças na burocracia, preocupação uníssona, como se viu, foram problematizadas em suas respectivas épocas, nomeando um inchaço da máquina administrativa, incluindo contratações de servidores com funções não específicas e tornando o Estado incompetente e perdulário (Uruguai, 2002; Oliveira Vianna, 1947; Ramos, 1966; Bresser-Pereira, 1995b).

Ao combater o que se veio a chamar de patrimonialismo, traço da cultura política nacional que impede o funcionamento racional do Estado, Uruguai preocupava-se com o fato de os julgadores das questões administrativas serem oriundos do mesmo local ao qual pertenciam os funcionários administrativos julgados (Uruguai, 2002); Oliveira Vianna temeu profundamente as relações clânicas provenientes das relações entre os senhores de terras e seus súditos e como essa relação impregnava a máquina do Estado (Oliveira Vianna, v. 1 e 2, 1987a; 1987b); Guerreiro Ramos (1966) e Bresser-Pereira (2009) encontravam-se mais próximos, nessa reflexão, sendo o primeiro ator da Reforma Burocrática que pretendeu eliminar o patrimonialismo do Estado pela via dos concursos públicos, iniciativa por Bresser buscada na Reforma Administrativa de 1995 pela política de parcerias para as atividades públicas com o setor público não estatal.

A questão do desenvolvimento nacional surge em todos os autores. Para Uruguai (2002) e Oliveira Vianna (1987) era variável dependente da cultura nacional. Essa relação se inverte com as teses da Cepal e do Iseb, que percebem a mudança cultural a partir de uma perspectiva desenvolvimentista. Para Guerreiro Ramos (1966), a partir da constituição de um sistema capitalista, as relações sociais mudariam, integrando as pessoas em um mercado próprio, elemento faltante para que o povo pudesse organizar-se e rumar em direção à democracia.

Bresser-Pereira (2009), pode-se dizer, é partidário dessa segunda relação, que não desmerece a questão cultural e faz eco ao "problema nacional" da inexistência de 
um povo e coloca a variável "cultura" como dependente do desenvolvimento econômico. Como os demais, ao pensar o fortalecimento da democracia e a criação de um "Estado republicano", as reformas propostas e implementadas pelo ex-ministro Bresser tratam de reformas orientadas para o mercado, com forte caráter de regulação estatal, uma vez que essa relação capitalista é que favoreceu o surgimento de um Estado social-liberal (Bresser-Pereira, 2009).

Essa reforma também logrou fortalecer o núcleo estratégico do governo, bem como incentivar a participação e o controle sociais por intermédio da publicização de serviços não exclusivos do Estado, como os serviços de saúde e cultura, por exemplo ${ }^{17}$.

Supôs-se que, por intermédio das reformas da estrutura político-administrativa feitas por Bresser-Pereira, se alcançaria o almejado Estado republicano, uma vez que elas elevariam a capacidade organizacional da comunidade nacional ou, como disse Bresser em outro lugar, a reforma do Estado teria a capacidade de democratizar a sociedade civil a partir de sua participação na execução das políticas públicas do Estado (Bresser-Pereira \& Grau, 1999).

\section{Reflexões finais}

O que aqui se buscou demonstrar é o fato de que os autores-atores tratados convergiram do ponto de vista das ideias em como alcançar e fortalecer a democracia no país por meio de reformas nas instituições político-administrativas nacionais.

As diferenças apontadas demonstram a maneira como cada um manuseou a realidade social e política que a história e a morfologia social nacionais se Ihes impingiu durante suas reflexões.

Não se pode, em uma proposta como a que foi aqui desenvolvida, cair na tentação de análises anacrônicas. Conclusões normativas e temporalmente mal colocadas como a de cobrar que Uruguai fosse favorável ao fim do Império no início do século XIX escravocrata, por exemplo, ou que Oliveira Vianna propugnasse a descentralização política, dado o caráter patrimonialista da sociedade do início do século XX. É impossível se dizer de Guerreiro Ramos que sua visão messiânica para a sociedade nacional estava equivocada em meados dos 1950 e que a relação que ele estabeleceu entre desenvolvimento econômico e democracia fosse espúria.

Possível é, todavia, perceber nas ideias desses autores traços comuns: todos - aqui se incluindo Bresser-Pereira - foram partidários da tese de que a mudança na cultura política da sociedade brasileira conduziria o país ao self-government, à democracia e à sua qualificação. Mais do que isso: essa mudança poderia ser favorecida pela

\footnotetext{
17. Publicização é atividade de transferir para o setor público não estatal esses serviços através de um contrato de gestão.
} 
reforma das instituições político-administrativas do Estado brasileiro, conferindo a esse Estado nuances de pedagogo da liberdade.

Uma última discussão se mostra necessária, todavia, no âmbito destas breves reflexões finais. Como se pode notar, as ideias dos autores selecionados tiveram suas reflexões, em regra, associadas ao autoritarismo e/ou ao conservadorismo.

Nessa linha de raciocínio, perguntam-se pesquisadores contemporâneos sobre a relação de subordinação da sociedade em relação ao Estado estabelecida por esses autores e a subsequente chegada do Brasil à categoria de nação democrática. Necessitar-se-ia, de fato, que o moderno, tendo sua forma política representada pelas instituições democráticas, para ser implantado, passasse pela tradição representada por certa tutela estatal sobre a sociedade?

O próprio Guerreiro Ramos autotitulou-se de pragmático crítico (1960), ao lado de Uruguai e Oliveira Vianna. Essa tradição, todavia, também foi associada ao que autores usam chamar de iberismo, conceito que, ao pensar a identidade ibérica, espeIha o anseio de uma comunidade nacional organizada hierarquicamente sob o pálio da autoridade.

Esclarece José Murilo de Carvalho que o iberismo pode ser compreendido como

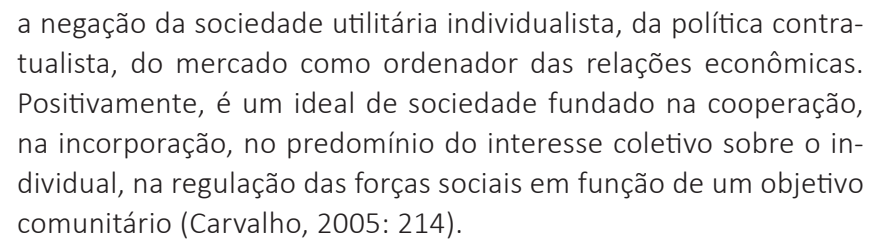

Outrossim, o Estado tem papel central tanto na manutenção da ordem social como no encaminhamento da nação rumo ao moderno, devido à sua anterioridade em relação à sociedade.

Esta compreensão defende a tese de que o governo deveria adotar atitudes que orientassem a condução do povo ao autogoverno; perspectiva que oferece contornos pedagógicos ao Estado, que não seria um fim em si mesmo, mas uma etapa necessária à implantação de liberdades políticas plenas. Wanderley Guilherme dos Santos (1978) argumenta que esse seria um Estado "autoritário instrumental", ocupado da maneira como as elites promoveriam uma maciça mudança cultural na sociedade a partir de cima, pressupondo o autoritarismo enquanto instrumento provisório para que se instaurasse no país uma sociedade talhada para lidar com instituições liberais autênticas. 
Bolívar Lamounier (2003), ao analisar essa corrente de pensamento, a vincula a "duas metades do organicismo romântico", que foi a corrente intelectual responsável pela unicidade de duas ideias contraditórias: uma conservadora, outra revolucionária. Assim, a partir de 1870, a parte conservadora se une ao positivismo, resultando em uma "sociologia histórico-organicista" que teria influenciado críticos elitistas da democracia liberal como Mosca, Pareto e Michels. Já a metade revolucionária ter-se-ia inspirado em aspecto fáustico e carismático do romantismo, tendo demonstrado sua face política de maneira voluntarista e mobilizante, seja por meio de uma deificação da nação e do Estado, seja em manto anarquista.

No Brasil, essas ideias associaram-se às preocupações vigentes no Império em relação à unidade e à estabilidade do regime e se teriam investido de nova importância com a intensa urbanização e a progressiva instauração de uma sociedade de massas no país. Diz o autor:

Pois bem: a absorção deste mundo de ideias na ideologia estatal-centrista brasileira se deu através de uma acentuação do elemento positivista e dos aspectos conservadores da linguagem organicista. Dentro desta perspectiva, é palpável a adequação da metáfora organicista para expressar uma visão conservadora do próprio processo de mudança que se pretende acionar, ressaltando a perdurabilidade do passado no presente, a concepção do crescimento e da mudança como desenvolvimento de um princípio interno contido na origem, a indispensável maturação do corpo social antes da efetivação de reformas ou enxertos institucionais (Lamounier, 2003: 390).

Observa-se que um dos aspectos pelos quais se pode dizer que esses autores-atores foram conservadores é o fato de que as mudanças que propuseram na ordem nacional transitaram pelas instituições jurídicas, políticas e culturais vigentes em suas épocas, não tendo sido revolucionários. Um ponto mais importante do conservadorismo que os une é sua percepção de que o povo deva ser treinado para a democracia ou seu aperfeiçoamento. Durante esse processo, pode-se conviver durante alguns períodos com a falta, ou diminuição, das liberdades políticas formais, mas essa falta, como se percebe em seus argumentos, não seria condição suficiente, sequer necessária, para a indispensável tutela do povo rumo à liberdade.

Uruguai, a despeito do Regresso, nunca propôs contra a representação política; Oliveira Vianna participou como servidor tanto do governo do Estado Novo quanto do período democrático iniciado em 1945; Guerreiro foi assessor de Vargas e teve seus direitos políticos cassados pelo Ato Institucional n.o 1; Bresser rompeu com seu partido político por esse ter apoiado a UDN ${ }^{18}$.
18. Uruguai promoveu o Regresso pela via constitucional. Oliveira Vianna não participou da Revolução de Getúlio, tendo sido intelectual orgânico de seu governo quando já instalado - como também o foi, nos últimos sete anos de vida, de governos democraticamente eleitos (19451952). Guerreiro propôs mudanças constitucionais no período 1945 1964 e lutou com suas armas intelectuais contra o Regime Militar. Bresser, confesso admirador de Vargas (Bresser-Pereira, 2004), rompe com o PDC em 1955 por discordar do apoio oferecido a Juarez Távora (UDN) em detrimento a Juscelino Kubitschek, e ingressa em atividades governamentais na Nova República. 
As reflexões e os planos de ação traçados e executados pelos autores-atores aqui apresentados, se não se os pode vincular diretamente ao processo de democratização alcançado pela nação brasileira (seja por falta de dados empíricos que permitam esse movimento neste artigo, seja antes porque este não era o escopo deste trabaIho), deixam a suposição de que a relação exista.

Abstract: The organization and structure of Brazilian central government have drastically changed from monarchic period (1824-1889) to the recent democratic time. However, it is possible to identify a convergence between some Brazilian authors who have, not only reflected about state reform in Brazil, but have acted on it: visconde do Uruguai (minister and Senator during the first empire period in Brazil, responsible for an important state reform at his time - 1830 to 1852); Oliveira Vianna (bureaucrat on Getulio Vargas's term and responsible for important changes in state structure and its relation with trade unions in Brazil during the 1930's); Guerreiro Ramos (sociologist and bureaucrat at Public Service Administration Department responsible for the Brazilian bureaucratic state reform from 1940 to 1964); and Bresser-Pereira (minister of Ministry of Federal Administration and State Reform during Fernando Henrique Cardoso's first term - 1995 to 1998 who was responsible for the current managerialization of the Brazilian state). What is interesting to note about these political author-actors actors is that, during their respective periods and with their unique perceptions about Brazilian policy and society, they believed that by reforming the administrative structure of the state they could change political culture of the Brazilian people. During their political actions as Brazilian bureaucrats they each searched for the self-government, the democracy or its qualification within their own historical and political contexts.

Keywords: political culture, structure of the State, brazilian political thoughts, government, society.

\section{Referências}

ALMEIDA, Maria Hermínia Tavares de. Oliveira Vianna, instituições políticas brasileiras. In: MOTA, Lourenço Dantas (Org.). Um banquete no trópico. Vol. I. São Paulo: Editora Senac, 2001.

ALMOND, Gabriel; VERBA, Sidney. The civic culture. Thousand Oaks (CA): Sage, 1963.

ARRUDA, Mário Hélio de; MENDONÇA, Carlos Vinicius Costa de. Oliveira Vianna: ideologia social autoritária. Revista Ágora, n. 3, p. 1-21, Vitória, 2006.

AVELLAR, Helio de Alcântara. História administrativa e econômica do Brasil. 2. ed. revista e atualizada. Rio de Janeiro: Fename, 1976.

BARBOSA, Lívia. Cultura política. In: NAKANO, Y.; REGO, J. M.; FURQUIM, L. (Orgs.). Em busca do novo: o Brasil e o desenvolvimento na obra de Bresser-Pereira. Rio de Janeiro: Editora FGV, 2004.

BONAVIDES, Paulo; ANDRADE, Paes de. História constitucional do Brasil. Rio de Janeiro: Paz e Terra, 1991. 
BRANDÃO, Gildo Marçal. Linhagens do pensamento político brasileiro. São Paulo: Hucitec. 2007.

BRASIL. Decreto-Lei n. 579/1938. Disponível em: <www.mp.gov.br>. Acesso em: Maio 2010.

— Lei n. 9.637/1998. Disponível em: <www.mp.gov.br>. Acesso em: Maio 2010.

—. Presidência da República. Câmara da Reforma do Estado, Plano Diretor da Reforma do Aparelho do Estado, 1995.

BRESSER-PEREIRA, L. C. Construindo o Estado republicano: democracia e reforma da gestão pública. Rio de Janeiro: Editora FGV, 2009.

- Economista ou sociólogo do desenvolvimento. NAKANO, Y.; REGO, J. M.; FURQUIM, L. (Orgs.). Em busca do novo: o Brasil e o desenvolvimento na obra de Bresser-Pereira. Rio de Janeiro: Editora FGV, 2004.

Why did democracy became the preferred form of government only in twentieth century? In: Encontro da ABP 3, Anais, Niterói, 2002. Disponível em: <www. cienciapolitica.org.br>.

—. Reforma do Estado para a cidadania. São Paulo: Editora 34. 1998.

_. Estado, sociedade civil e legitimidade democrática. Lua Nova, n. 36, p. 85104, 1995a.

- Modernização incompleta e pactos políticos no Brasil. In: SOLA, L.; PAULANI, L. M. (Orgs.). Lições da década de 80. São Paulo: Edusp, 1995b.

BRESSER-PEREIRA, L. C. et alii. State reform in the 1990s: logic and control mechanisms. Disponível em: <http://www.bresserpereira.org.br/papers/1997/95-StateReformInThe1990s.pdf>. Acessado em: 13 Jun. 2012.

BRESSER-PEREIRA, L. C.; GRAU, Nuria Cunill (Orgs.). O público não-estatal na Reforma do Estado. Caracas; Rio de Janeiro: Clad; Fundação Getúlio Vargas, 1999.

BRESSER-PEREIRA, L. C.; MARAVALL, José Maria; PRZEWORSKI, Adam. Economic reforms in new democracies: a social-democratic approach. In: SMITH, W. C.; ACUÑA, C. H.; GAMARRA, E. (Eds.). Theoretical and comparative perspectives for the 1990s. New Brunswick: Transactions Books. 1994.

CARVALHO, José Murilo de. A utopia de Oliveira Vianna. In: CARVALHO, J. M. Pontos e bordados, escritos de história e política. Belo Horizonte: Editora UFMG, 2005.

Visconde do Uruguai. Editora 34. São Paulo. 2002. 
CARVALHO, José Murilo de (Org.). Bernardo Pereira de Vasconcelos. São Paulo: Editora 34, 1999.

DINIZ, E.; AZEVEDO, S. (Orgs.). Reforma do Estado e democracia no Brasil. Brasília: Editora UnB, 1997.

DOLHNIKOFF, Miriam. Império e governo representativo: uma releitura. Cad. $\mathrm{CRH}$, v. 21, n. 52, Salvador, Jan.-Abr. 2008.

LAMOUNIER, Bolívar. A formação do pensamento político autoritário na Primeira República. Uma interpretação. In FAUSTO, Boris (Org.). História geral da civilização brasileira, Vol. IX. Rio de Janeiro: Bertrand Brasil. 2003.

LEAL, Carmem Imaculada de Brito Almeida. A Ação Católica em Minas Gerais. Teoria e Sociedade, número especial em homenagem a Fernando Correia Dias, p. 152-161. Minas Gerais, 2004.

MACEDO, U. Origens nacionais da doutrina da ESG. Convivium, n. 225, p. 514-518, São Paulo, Set.-Out. 1979.

MARSHALL, T. H. Cidadania, classe social e status. Rio de Janeiro: Zahar, 1967.

MELO, Marcus André. Republicanismo, cidadania e (novos?) direitos. In: NAKANO, Y. et alii (Orgs.). Em busca do novo. O Brasil e o desenvolvimento na obra de Bresser-Pereira. Rio de Janeiro: Editora FGV, 2004.

MICELI, Sérgio. História das ciências sociais no Brasil, Vol. 2. São Paulo: Sumaré, 1995.

— (Org.). História das ciências sociais no Brasil, Vol. 1. São Paulo: Vértice, 1989. MOISÉS, José Álvaro. Os brasileiros e a democracia. São Paulo: Ática. 1995.

O'DONNELL, G.; SCHIMITTER, P. Transitions from authoritarian rule - tentative conclusions. Baltimore: John Hopkins Press, 1988.

OLIVEIRA, Lucia Lippi de. A sociologia do Guerreiro. Rio de Janeiro: Editora da UFRJ, 1995.

OLIVEIRA VIANNA, F. J. de. Instituições políticas brasileiras, Vol. I. São Paulo: Edusp, 1987a.

\footnotetext{
—. Instituições políticas brasileiras, Vol II . São Paulo: Edusp, 1987b.

_. Populações meridionais no Brasil. Rio de Janeiro: Paz e Terra. 1973.

—. Problemas de política objetiva. São Paulo: Companhia Editora Nacional. 1947.
} 
PRZEWORSKI, Adam; CHEIBUB, José Antônio; LIMONGI, Fernando. Democracia e cultura: uma visão não culturalista. Lua Nova, n. 58, São Paulo, 2003.

RAMOS, Alberto Guerreiro. Administração e estratégia do desenvolvimento: elementos de uma sociologia especial da administração. Rio de Janeiro: Editora da FGV, 1966.

—. O problema nacional do Brasil. 2. ed. Rio de Janeiro: Saga. 1960.

—. A divisão do trabalho social. Revista do Serviço Público, v. 4, n. 1-2, p. 161168, Rio de Janeiro, Out.-Nov. 1946.

REIS, José Carlos. As identidades do Brasil 2. Rio de Janeiro: Editora FGV, 2006.

RODRIGUES, José Honório. A metafísica do latifúndio. O ultra-reacionário Oliveira Vianna. In: RODRIGUES, José Honório. História da história do Brasil. São Paulo: Nacional. 1988.

ROMÃO NETTO, José Veríssimo. Estado, o pedagogo da liberdade: reformas das instituições político-administrativas do Estado e cultura política nacional no Brasil Império e República. Tese (Doutorado) - Departamento de Ciência Política, Universidade de São Paulo, São Paulo, 2010.

- Instituições de participação popular direta em saúde e cultura democrática: o caso dos conselhos gestores de saúde das subprefeituras de São Paulo. Dissertação (Mestrado) - Departamento de Ciência Política, Universidade de São Paulo, São Paulo, 2006.

SADER, Eder. Quando novos personagens entram em cena. Rio de Janeiro: Paz e Terra, 1988.

SOLA, L. Estado, reforma fiscal e governabilidade. Novos Estudos Cebrap, n. 38, 1994.

SANTOS, Wanderley Guilherme. Ordem burguesa e liberalismo político. São Paulo: Duas Cidades, 1978.

URUGUAI, Visconde do. Ensaio sobre o direito administrativo. In: CARVALHO, J. M. (Org.). Visconde do Uruguai. São Paulo: Editora 34, 2002.

VIANNA, Luiz Werneck. O moderno na política brasileira. Presença, n. 5, p. 37-56, São Paulo, Jan. 1985.

WEFFORT, Francisco C. Formação do pensamento político brasileiro: idéias e personagens. São Paulo: Ática. 2006. 